\title{
Evaluating the Power of CORE
}

\author{
Karen E. Efford, Jillian Roberts \\ University of Victoria, Canada
}

\begin{abstract}
Tutors are often found outside of the regular classroom and often in community settings. By building a unique relationship with their students, tutors are able to play an important role in the lives of their students. Tutors at the Centre for OutReach Education (CORE) endeavor to do just that. Located at the University of Victoria, CORE is a multidisciplinary centre dedicated to enhancing the education of children and youth. CORE's aim is to fill unmet needs in the community by supporting students who might not necessarily be able to afford such educational support in the community context. CORE Tutors are hired primarily from the body of students in the University of Victoria's Education (teacher training) programs. CORE's provides these teachers in training with a unique opportunity to hone their skills while supporting children in need. CORE pairs tutors with one student for the period of one or two academic terms allowing for a supportive relationship to form and where the tutors understands the academic need of their respective students. The purpose of the present case study is to gain insight into the specialized role of tutors and how this hands-on experience influences their pedagogical practice. Using a case study, the reflections of tutors in the 2015-2016 cohort will be examined and this data will help us to better understand the role CORE plays in the training of student teachers.
\end{abstract}

\section{Introduction}

The 21st century educational world is changing. The complexities of children's needs are changing and schools may not be able to step up and meet these needs [8]. Outreach programs such as CORE provides a supportive, individual program, which increases the possibility of student success. At CORE, not only are students in community receiving educational support but also student teachers are given the opportunity to practice their skills creating a community partnership. Tutoring provides an opportunity to connect with a student and provide academic support often not afforded in a traditional teaching environment. "Tutoring is a very old practice. It was common in Ancient Greece and Rome, and is recorded in ancient texts even before then. Over the centuries it has gone up and down in popularity, but it has never gone away" [9]. This age old practice can provide a greater quantity of educational support to an individual student.
Working at CORE is a valuable way to gain experience working with students with special learning needs, to develop and practice teaching skills while receiving ongoing feedback, and to contribute to the community. The purpose of this study is to gain insight into the specialized role of tutors and how this hands-on experience influences their practice as classroom teachers. This article will provide background information on CORE and then will provide the results from the case study inquiry. Throughout the sharing of results, an in depth discussion will be offered.

\section{Background}

The Centre for OutReach Education (CORE), located at the University of Victoria's Faculty of Education, is a multidisciplinary centre whose focus is to support children and youth in the community through alternative educational practices. CORE was created to provide education to children in need, through a generous donation from an anonymous donor who was a former primary school teacher. These funds were donated with the specific wish that they be used for the benefit of children's education. CORE is guided by a committee made up of faculty members from several departments including, Education, Psychology, Psychology and Leadership and the School of Exercise Science, Physical and Health Ed overseen by the Dean of Education.

Families from low socioeconomic status (SES) backgrounds are identified as a vulnerable population as children from these families are often at risk for poor educational outcomes [4]. These families often struggle financially trying to provide additional educational support privately. Children with "invisible disabilities" such as: learning disabilities/difficulties; mild intellectual disabilities; or emotional disorders, were recognized by the CORE committee as a key community groups who would most benefit from educational support and services. All CORE programs are provided free of charge. CORE provides this opportunity.

There are three foundational CORE programs: CORE Club, CORE Mobile and Tools for Success. CORE Club is the foundational program located on campus. CORE Club is an on campus tutoring program which pairs undergraduate and graduate students with children in the community for one or two academic terms. These student/tutor pairs meet either once or twice a week depending on the group. CORE Mobile supports community-tutoring program 
at Songhees First Nation by providing tutors from the university for one or two academic terms. This program is currently being expanded to other Nations in the Greater Victoria area. Tools for Success is a tutoring program established by the University of Victoria and HeadWay, Victoria Epilepsy \& Parkinson's Centre. CORE has recently (2016) taken over this program, and matches children with Epilepsy who also struggle with academic success with University of Victoria students. CORE is currently expanding this program to support children who are diagnosed with other co-occurring exceptionalities such as Autism Spectrum Disorder. All tutors are provided with the opportunity for professional development through monthly workshops in areas that support their work at CORE. These workshops cover topics such as: Seizure management; technology in education; art education; and tools to support student with dyslexia and dysgraphia.

CORE's active engagement in community programming goes beyond the foundational programs. Through offering space year round, CORE support Inclusion Works, an individualized, age appropriate, community-based program for young adults with developmental disabilities. CORE also provide grants of up to $\$ 10,000 /$ year to community programs which provides funding for a wide range of programs that support and serve children in the community. This year's recipients include:

- Family Workshops for Disorders in SelfRegulation (Attention Deficit Hyperactive Disorder)

- Music Circles: A creative musical opportunity for Down Syndrome young people.

- Finding Voice and Identify Through Multi-modal Literacies

- Girls Get Active: A multi-grade physical activity initiative at Spectrum Community School.

The following vignette describes a day at CORE.

At 4pm, four days a week in a corner on the $3 \mathrm{rd}$ floor of the Faculty of Education at the University of Victoria, tutors start to trickle in, some in groups of two or three and some alone. They have been in class and are a mixture of tired and excited. As they walk past my desk we share a smile and check in. Gathering in one of the rooms, some pull out a snack and some check their phones, all the while discussing curriculum or pedagogical ideas covered in their classes that day. This is an opportunity for them to share ideas and scaffold their own learning. Over the next half hour they slowly come to discuss their students soon to arrive, picking up the student's folders, reviewing last session's progress and gathering material for this day's session. One of them asks me to print off a worksheet and slowly others ask about resources that might address their student's particular academic struggle. Each day is different as the tutors strive to meet their student's unique needs and engage them where they are on that particular day. As 4:30 approaches the CORE students arrive, check in, find their tutor and share stories from their day. It is a tight, busy space with 15 tutors and 15 students greeting each other and making plans for their 90 minutes together. Some choose a room in the CORE space, some wander off to find an empty classroom in the building, while others get together in small groups and start their session playing a game outside in the sunshine, a much needed break for students who have spent the day in school. The connection between tutor and student grows as the term progresses and they look forward to seeing each other. The tutors are invested in their student's progress in school and strive to provide needed academic support.

\section{Methodology}

The primary goal of this research project is to understand whether the role of tutor for the CORE program provides added educational and work experience to the students in the pre-service teacher program at the University of Victoria. This case study focuses on new teachers' perspectives on teaching and learning in the CORE environment for the $2015 / 2016$ University fall and winter terms. The participants were undergraduate and graduate student primarily from the department of Education in either the Post Degree Professional program (PDPP), the Teacher Education or Art Education programs who had been hired as tutors. Participants were predominately female, between the ages of 18-25 years with limited teaching experience. Most of the tutors have completed a class on differentiated instruction. This study is informed by case study methodology that aims to take the responsibility of evaluating the CORE program [11]. As the Case Study researcher's primary responsibility is to maximize what we can learn in a "bounded system", placing a worker in the field provides the opportunity for ongoing observation. The primary researcher of this study is the Coordinator of the CORE program therefore has the ability to evaluate the program on an ongoing basis. [11] Using descriptive data collected from ongoing reflective journaling guided by questions completed by the tutors, with the goal of showing how this program influences the rich perspective of education. As tutors work directly for the Coordinator the questionnaires were online and anonymous to protect participants from power-over relationships. The tutors were invited to participate in this case study by a Faculty member and did not discuss the study with the Coordinator. The primary researcher collected and analyzed the data. The questions focus on gaining insight into the experience of the tutors and how this experience 
might have supported their future positions of teacher in the community.

There were four main themes identified by the tutors in this study:

- That CORE provides experience and preparation for teaching.

- There is a need for or value in individualized instruction.

- Being a facilitator rather than a lecturer and working together (tutor \& student) is a valid teaching model.

- CORE Environment as a positive learning space Finally, participants were asked what, if any recommendations they might have to further support this program. In the Discussion section, the responses from participant tutors, outlined in boxes, are shared with the above themes as guides.

\subsection{Teacher preparation}

CORE provides tutors with the opportunity to apply their knowledge and adapt teaching strategies to meet the individual needs of their students. This experience contributes to their professional development as future teachers.

Mentoring is a seen in many different contexts. In the context of CORE, other tutors, faculty members, as well as the CORE Coordinator mentor the tutors on an on-going basis. Mentoring can be defined as one-on-one support of a novice or less experienced teacher by a more experienced teacher designed primarily to assist the development of the mentee [1]. "Research has shown that the potential positive outcomes of mentoring are substantial; indeed some studies suggest that mentoring may be the single most effective method of supporting the professional development of beginning teachers" [1].

Teachers are important role models in a student's life. They are in a unique position to guide a young person by providing supportive educational opportunities. The tutor student relationship creates a positive learning environment, which can tap into their interests and support a student's natural instinct to learn. "For most young people, learning matters when it is personal and serves a purpose. When students have an opportunity to use or share what they know, they want to learn more" [13].

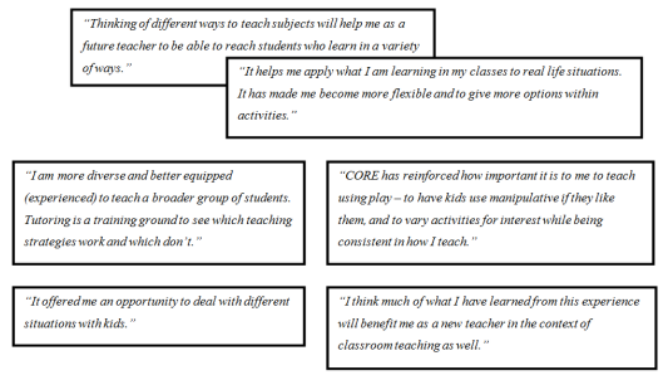

Tutors offer diverse approaches to learning are key to supporting student who learn in different ways.

\subsection{Individualized Instruction}

Individualized Instruction and student-centered learning is a curricular approach in which students are given a degree of agency over when, how or what to learn. Historically, influential theorists such as Rousseau, Pestalozzi, Dewey and Vygotsky focused their educational theory on the importance on honoring the natural needs of the individual child. Rousseau's freedom-based education gives children the freedom to be guided by their own interests. Education should "honor the dignity and autonomy of each individual by allowing her to freely discover her own life's meaning through the exploration of her interests, rather than being made to study some pre-arranged sets of knowledge at a standard pace" [6]. John Dewey work outlined beliefs in meaningful, curriculum focusing on a child's ability and interests. He believed a teacher should provide guidance rather than impose ideas [3]. Tutoring provides the opportunity to de-emphasize the traditional role of students and take on a role of facilitator guided by the student's unique interests and learning styles.

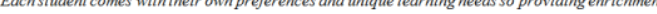

and applying teaching strategies looks differentfor each student.

\subsection{Facilitator}

Russian psychologist, Lev Vygotsky's Zone of Proximital Development's (ZOPD) key element is the interaction between a child's development and instruction. Meeting a child at the edge of their

"I am more useful to my students if I make myself more of a facilitator of their learning rather than a vessel of knowledge that is "poured" into my students."

knowledge and assisting them in the next step allows the child the ability to reach that next step on their own [10]. This is echoed by Topping in his booklet on tutoring when he says: " Tutoring should start at the tutee's current point of understanding. Tutors must establish where this is, and uncover relevant misconceptions. Tutoring must then proceed in small steps from this point" [9]. At CORE we strive to provide the tutors with the tools, as well as the freedom, to address their student's learning needs and support those needs through facilitating individualized instruction. Tutors are able to explore their student's level of understanding and take small steps to balance support and challenge. The one-onone relationship creates consistency and the opportunity for support without negative feedback. 
Tutors are encouraged to find another way, think outof-the-box if the student doesn't understand and not fall back on a prescribed lesson plan. This builds knowledge through alternative methods not always accessible in a school classroom. "Inow understand that all students are different and understand things differently, if as a teacher take
a certain level of understanding for grantedI am robing the students who do not yet understand the basics of the opportunity to learn.

"Just because a student CAN do something does not mean they understand what they are doing and
why they are doing it."

\begin{tabular}{|l|l|}
\hline $\begin{array}{l}\text { "CORE has taught me that I need to be responsive } \\
\text { andflexible to apply and interpret student learning } \\
\text { needs based on more of an ongoing assessment } \\
\text { process during the actually teaching interaction." }\end{array}$ & $\begin{array}{l}\text { "The program has also reinforced to me the } \\
\text { important of learning through play and the } \\
\text { importance of individualized lessons to make } \\
\text { themrelevant to the kids I teach." }\end{array}$ \\
\hline
\end{tabular}

\subsection{Positive Learning Space}

CORE strives to provide tutors with a supportive environment where tutors' primary responsibility is to their student but of equal importance is their own professional development. Tutors who responded to the survey expressed the fact that working at CORE provided reinforcement of some preconceived ideas surrounding teaching but also provided the opportunity to change some perspectives.

"CORE has definitely reinforcedfor me the importance of creating, and working in, a supportive environment that fosters collaboration and an exchange of ideas."

"Being a CORE tutor will help me to plan lessons, work with students with learning difficulties, and figure out which resources are most helpful for students - and for teachers."

\section{Conclusion}

In their 2008 study, Teacher Education in Canada, A Baseline Study, Crocker, Robert, Dibbon and David 1[7] look at the preparation of teachers in programs across Canada. Their findings include that "the demand for more classroom experience was a persistent theme" [7] in their research. The main gap in teacher education programs was identified as transition programs, teaching students w/disabilities and motivating students to learn. "This points to a universal formal induction and mentoring program" [7]. Given that Faculties of Education's core business is teaching and learning, Crocker et al propose that "this work needs to be done in partnership. The Centre for OutReach Education provides a mentorship model, which includes professional development workshops, direct instruction with student with a wide variety of learning challenges and collaboration with other preservice teachers. The primary goal of this study was to determine to gain insight into the role of tutors in the CORE environment and how this individual instruction model influences their practice as future teachers. In order to support this goal, participants in the study were ask what additions or changes could inform CORE's practices going forward. The following are a list of suggestions from the surveys:

- More places to work one-on-one

- More information on what kind of resources are available at CORE.

- More resources available for new tutors.

- More opportunities to debrief with other tutors throughout the term.

These suggestions will be implemented for the fall 2016 tutor co-hort by advising tutors of the opportunities for using space within the Faculty of Education, providing a through list of resources and where to find them, and organizing formal monthly tutor debrief sessions.

Teacher candidates working as tutors at the Centre for OutReach Education are a key component to community based learning. 21 century learning will need to adapt to student needs and be supported by community stakeholders. Programs such as CORE provide an opportunity for the University to provide "on the job" training to their education students while supporting educational need to children and youth who benefit from the outreach initiative enabling them to grow, learn, and thrive. Initially started by the donation of one individual, through the hard work of partners and the collaboration of many, CORE has been able to succeed and grow. Although there is strong evidence to demonstrate the positive effect of CORE on the education of future teachers, it would be important to expand this study. In order to present a complete and rich program evaluation of CORE, it would be necessary include the experience of more tutor participants, evaluate student progress over the two terms and interview parents whose children are students at CORE.

\section{References}

[1] A.J. Hobson, "Face-to-Face Mentoring \& Coaching", In S.J. Fletcher \& C.A. Mullen(Eds.), SAGE Handbook of Mentoring and Coaching in Education. (4), SAGE Publications, US, 2012.

[2] J. Abbott, "Battling for the Soul of Education", Retrieved from www.battlingforthesoulofeducation.org, 2000.

[3] J. Dewey, "My Pedagogic Creed", School Journal 54. Retrieved from http://dewey.pragmatism.org/creed.htm, 1897.

[4] J. Roberts, N. Popadiuk, and S. Helm, "Centre for OutReach Education: Making a CORE Difference", Proceedings from the International Academic Conference November 2012. 
[5] J.J. Rousseau, Emile, on Education, Dartmouth College Press, US, 2010.

[6] K. A. Morrison, "Unschooling". Encounter, 20(2), 2007, 42-49.

[7] K. Crocker, R. Dibbon \& C. David, "Teacher Education in Canada: A Baseline Study. Society for the Advancement of Excellence in Education", Retrieved from: http://site.ebrary.com/lib/uvic/detail.action?DocID $=10277017,2008$.

[8] K. Robinson, "Do Schools Kill Creativity?" TED Talk. Retrieved from http://www.ted.com/talks?sort=newest $\& q=$ Ken+Robinson, 2006.

[9] K. Topping, "Tutoring", In Educational Practices Series. (5). Belguin: International Academy of Education (IAE), 2000, www.ibe.unesco.org

[10] L. Vygotsky, Critical Assessment, Vygotsky's Theory, Routledge US, 1999.

[11] R.E., Stake, "The Art of Case Study Research", Sage Publications, US, 1995.

[12] M.B. Miles, A.M. Huberman and J. Saldana (Eds), "Qualitative Data Analysis, A Methods Sourcebook," Sage Publications, US, 2014.

[13] M. McLaughlin and M. Blank, "Creating a Culture of Attachment: A Community-as-Text-Approach to Learning”, Education Week, 24(11). 2004, 34-35. 